\title{
Functional Imaging of Dentate Granule Cells in the Adult Mouse Hippocampus
}

\author{
(10Gregor-Alexander Pilz, ${ }^{1 *}$ (i) Stefano Carta, ${ }^{2 *}$ Andreas Stäuble, ${ }^{2}$ Asli Ayaz, ${ }^{2}$ Sebastian Jessberger, ${ }^{\dagger}{ }^{\dagger}$ \\ and ${ }^{-F r i t j o f ~ H e l m c h e n ~}{ }^{2 \dagger}$ \\ Laboratories of ${ }^{1}$ Neural Plasticity and ${ }^{2}$ Neural Circuit Dynamics, Brain Research Institute, University of Zurich, CH-8057 Zurich, Switzerland
}

The hippocampal dentate gyrus is critically involved in learning and memory. However, methods for imaging the activity of its principal neurons, the dentate gyrus granule cells, are missing. Here we demonstrate chronic two-photon imaging of granule cell population activity in awake mice using a cortical window implant that leaves the hippocampal formation intact and does not lead to obvious alteration of animal behavior. Using virus delivery, we targeted expression of genetically encoded calcium indicators specifically to dentate gyrus granule cells. Calcium imaging of granule cell activity $600-800 \mu \mathrm{m}$ below the hippocampal surface was facilitated by using $1040 \mathrm{~nm}$ excitation of the red indicator R-CaMP1.07, but was also achieved using the green indicator GCaMP6s. We found that the rate of calcium transients was increased during wakefulness relative to an extremely low rate during anesthesia; however, activity still remained sparse with, on average, approximately one event per 2-5 min per cell across the granule cell population. Comparing periods of running on a ladder wheel and periods of resting, we furthermore identified state-dependent differences in the active granule cell population, with some cells displaying highest activity level during running and others during resting. Typically, cells did not maintain a clear state preference in their activity pattern across days. Our approach opens new avenues to elucidate granule cell function, plasticity mechanisms, and network computation in the adult dentate gyrus.

Key words: awake behaving animals; chronic activity measurements; red-shifted $\mathrm{Ca}^{2+}$ indicator imaging; two-photon imaging

\section{Significance Statement}

We describe a technique that allows for chronic, functional imaging of dentate gyrus granule cells in awake, behaving mice in an intact hippocampal circuitry using genetically encoded calcium indicators. This novel approach enables the analyses of individual granule cell activity over time and provides a powerful tool to elucidate the mechanisms underlying structural and functional plasticity of the adult dentate gyrus.

\section{Introduction}

The dentate gyrus (DG), part of the mammalian hippocampus, is critically involved in essential brain functions underlying certain

Received Aug. 14, 2015; revised April 28, 2016; accepted May 24, 2016.

Author contributions: F.H., S.J., G.A.P., and S.C. designed research; G.A.P., S.C., and A.S. performed research; A.A. and F.H. analyzed data; G.A.P., S.C., and A.S. contributed to data analyses; and S.J., F.H., A.A., G.A.P., and S.C. wrote the paper.

This work was supported by the European Molecular Biology Organization (EMBO) Young Investigator Program (S.J.), the Novartis Foundation (S.J.), the Swiss National Science Foundation (SNSF) Consolidator Program (S.J.), SNSF Grants 31003A-156943 (S.J.) and 310030-127091 (F.H.), and the SNSF Sinergia Project Grant CRSII3_147660/1 (F.H.).G.-A.P. was supported by an EMBO long-term fellowship. We thank L. Egolf for experimental support, Y. Sych for help with behavioral experiments, M. Ohkura and J. Nakai for R-CaMP1.07 plasmid, and J. Sobart and B. Weber for Cre-dependent R-CaMP1.07 virus.

*G.-A.P. and S.C. contributed equally to this work.

'S.J. and F.H. contributed equally to this work.

The authors declare no competing financial interests.

Correspondence should be addressed Sebastian Jessberger or Fritjof Helmchen, Brain Research Institute, University of Zurich, Winterthurerstrasse 190, CH-8057 Zurich, Switzerland. E-mail: jessberger@hifo.uzh.ch or helmchen@hifo.uzh.ch.

DOI:10.1523/JNEUROSCI.3065-15.2016

Copyright $\odot 2016$ the authors $\quad 0270-6474 / 16 / 367407-08 \$ 15.00 / 0$ aspects of learning and memory (Amaral et al., 2007; Jonas and Lisman, 2014). Through in vivo electrophysiological recordings and optogenetic silencing, the activity of dentate granule cells, the main excitatory neuronal cell population of the DG, has been associated with hippocampus-dependent behavioral pattern separation but also pattern completion (Leutgeb et al., 2007; Nakashiba et al., 2012; Neunuebel and Knierim, 2014; Danielson et al., 2016). These findings indicate a highly diverse contribution of granule cells to DG computation that appears to depend on the addition of newborn granule cells by neurogenic divisions of neural stem/progenitor cells that occurs throughout life in the mammalian DG (Clelland et al., 2009; Sahay et al., 2011; Spalding et al., 2013).

Whereas substantial progress has been made to study the functional properties of individual neurons in hippocampal area CA1 and deep neocortical layers (Levene et al., 2004; Mizrahi et al., 2004; Ziv et al., 2013; Lee et al., 2014; Rickgauer et al., 2014; Fuhrmann et al., 2015; Sheffield and Dombeck, 2015), activity patterns in the granule cell population and the contribution of 
adult-generated granule cells to DG function remain poorly understood. This is partly due to the lack of optical imaging methods for resolving granule cell activity within the intact hippocampal circuit in vivo, given that the DG is located several hundred microns deep below the ventral borders of the neocortex, which makes optical access to the DG difficult without interfering with or damaging overlying hippocampal structures. Consequently, DG granule cells have hardly been resolved structurally in vivo and have been imaged functionally in only one study so far (Gu et al., 2014; Kawakami et al., 2015; Danielson et al., 2016). Functional imaging of granule cell ensembles is, however, a prerequisite to further reveal fundamental principles of DG computation during encoding and expression of hippocampal engrams.

Here, we demonstrate chronic imaging of DG granule cell activity in the intact hippocampus in anesthetized and awake behaving mice by combining a chronic cortical window preparation with longwavelength two-photon excitation of either the red fluorescent protein calcium indicator R-CaMP1.07 (Ohkura et al., 2012) or the green fluorescent protein calcium indicator GCaMP6s (Chen et al., 2013). We confirm the sparseness of granule cell activity and demonstrate that activity patterns of DG granule cell populations are heterogeneous, depend on behavioral state, and vary flexibly across days.

\section{Materials and Methods}

Animals and R-CaMP1.07/GCaMP6s expression. All experimental procedures were conducted in accordance with the ethical principles and guidelines for animal experiments of the Veterinary Office of Switzerland and were approved by the Cantonal Veterinary Office in Zurich. We used transgenic mice with dense regional expression of Cre recombinase in layer 5 cortical pyramidal neurons and hippocampal granule cells (Rbp4KL100 BAC-cre line; Mutant Mouse Resource and Research Center No. 031125-UCD; Gerfen et al., 2013). To conditionally express R-CaMP1.07 in DG granule cells, we injected AAV1-EF $\alpha 1-D I O-R-C a M P 1.07$ viruses $\left(\sim 1 \times 10^{13} \mathrm{vg} / \mathrm{ml}\right)$ into the DGs of 5 - to 8 -week-old male and female Rbp4-KL100 BAC-cre mice ( $n=9$; Ohkura et al., 2012). In another set of four mice, we injected AAV9-CAG-FLEX-GCaMP6s (Chen et al., 2013) into Rbp4-KL100 BAC-cre mice to express this green calcium indicator in DG granule cells. Coordinates for stereotactic injections of adenoassociated virus (AAV) particles were as follows (from bregma, in $\mathrm{mm}$ ): $-2.0 \mathrm{AP},+1.5 \mathrm{ML}$, and $-2.3 \mathrm{DV}$ from the skull surface.

Cranial window preparation. Cranial window preparation followed a former description (Dombeck et al., 2010) and was performed under isoflurane anesthesia with body temperature being maintained at $\sim 37^{\circ} \mathrm{C}$ using a regulated heating blanket and a rectal thermal probe. The eyes of the mouse were covered by Vitamin A cream (Bausch \& Lomb) during the surgery. After disinfection with Betadine, the skin was opened with a scalpel, and the exposed cranial bone was cleaned of connective tissue and dried with cotton pads (Sugi). A circular piece of cranial bone (Ø 3 $\mathrm{mm}$ ) was removed using a dental drill with the injection site marking the center of the circle. Following the insertion of a biopsy punch $(\varnothing 3 \mathrm{~mm}$; Miltex) $1 \mathrm{~mm}$ deep into the cortical tissue for $2 \mathrm{~min}$, the cortical tissue
C
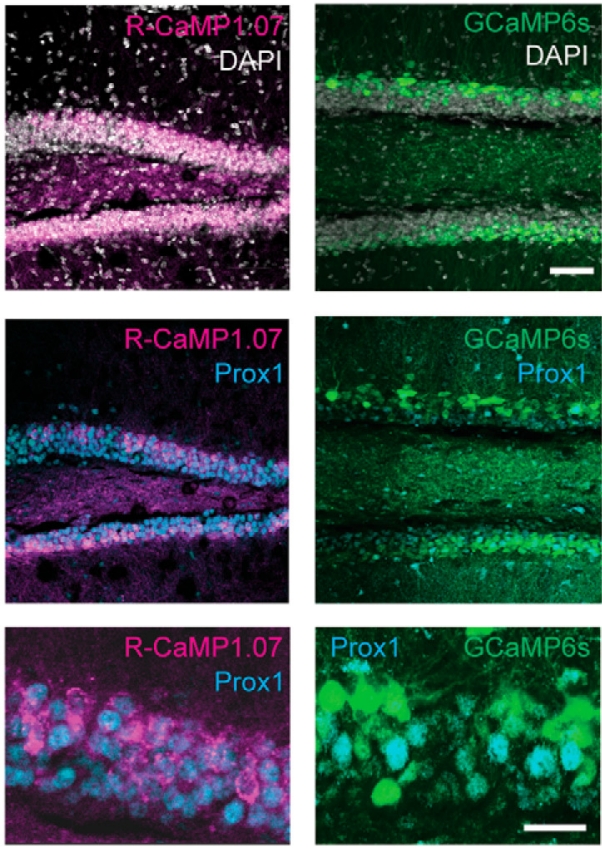

Figure 1. Imaging of genetically encoded calcium indicators expressed in DG granule cells of mouse hippocampus. $\boldsymbol{A}$, Schematic illustration of experimental setup showing the chronic window implant above the intact corpus callosum and area CA1 of the was confirmed by colabeling with nuclear DAPI (gray, top) and the granule-cell-specific transcription factor Prox1 (cyan, bottom). Scale bars: $\boldsymbol{B}, 1 \mathrm{~mm}$; $\boldsymbol{C}$, top, $50 \mu \mathrm{m}$; bottom, $20 \mu \mathrm{m}$.

was aspirated with a cut 27 gauge needle connected to a water jet pump. The cortical tissue was gently aspirated, while constantly being rinsed with Ringer solution, until the white matter tracts of the corpus callosum became visible. A stainless-steel cannula ( $\varnothing 3 \mathrm{~mm}, 1.5 \mathrm{~mm}$ height) covered by a cover glass ( $\varnothing 3 \mathrm{~mm}, 0.17 \mathrm{~mm}$ thickness) was inserted and secured in place by UV curable dental acrylic cement (Ivoclar Vivadent). To ensure reproducible positioning of the mouse by head fixation under the microscope objective, a small aluminum hook was glued to the skull on the contralateral side of the head with dental cement. Five days after the surgery, mice were first habituated to the experimenter by handling. Once familiar, animals were trained and accustomed to running on a running wheel placed under the two-photon microscope while being head fixed. The running speed of the mice was recorded in real time with a rotary encoder (Distrelec rotary encoder, incremental 5 VDC, 360, RI32-O/360AR.11KB, Hengstler) in parallel with calcium imaging of granule cell population activity.

Immunohistochemistry and confocal microscopy. After the last in vivo imaging session, animals received a lethal dose of pentobarbital (Eskonarcon, Streuli), were flushed with $\mathrm{NaCl}(0.9 \%$, sterile) until the liver turned pale, and subsequently were transcardially perfused with $4 \%$ paraformaldehyde (PFA; $0.1 \mathrm{M}$ phosphate buffer, $\mathrm{pH}$ 7.4). Brains were postfixed in $4 \%$ PFA (overnight at $4^{\circ} \mathrm{C}$ ) and dehydrated in $30 \%$ sucrose ( $0.1 \mathrm{M}$ phosphate buffer). Brains were cut into $40 \mu \mathrm{m}$ free-floating sections using a vibratome (Leica VT1200s). Immunohistochemistry using $\alpha$-Prox1 primary antibody (rabbit, 1:2000; Millipore Bioscience Research Reagents) was performed as described previously (Karalay et al., 2011). A secondary antibody conjugated to Alexa Fluor 488 or Cy3 was used to visualize Prox1. R-CaMP1.07 and GCaMP6s were not amplified by antibody staining, as the signal from these fluorescent proteins remained stable and strong after fixation and cutting. Fluorescence images of brain sections were acquired with a confocal laser-scanning microscope (Olympus FV1000) using 546 and $488 \mathrm{~nm}$ laser lines to excite 
A

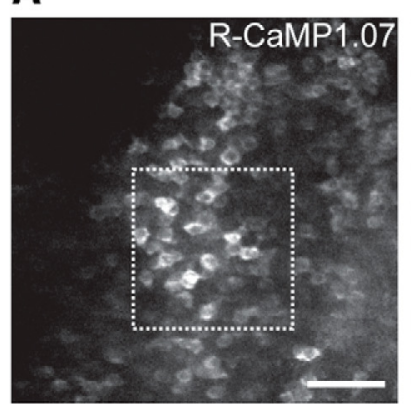

D

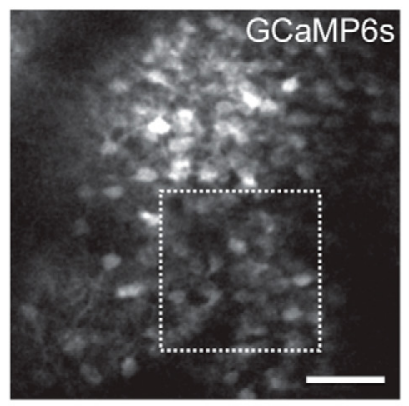

B
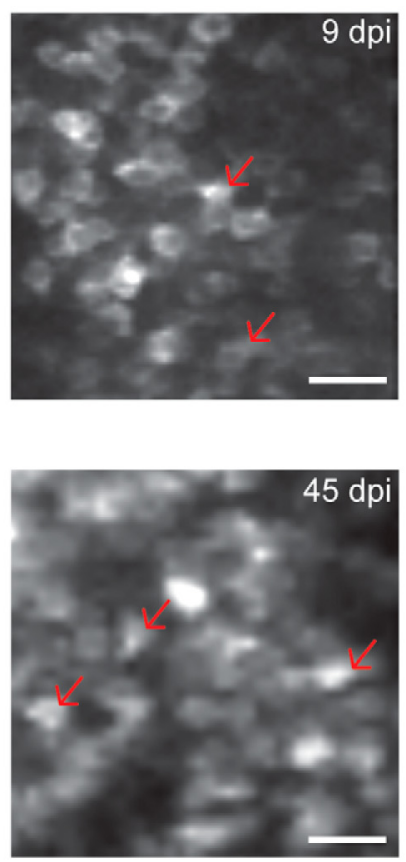

E
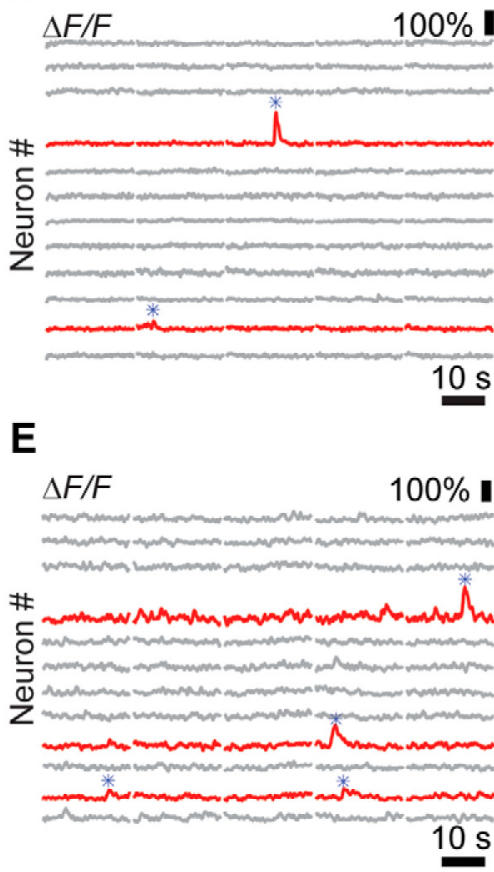

C
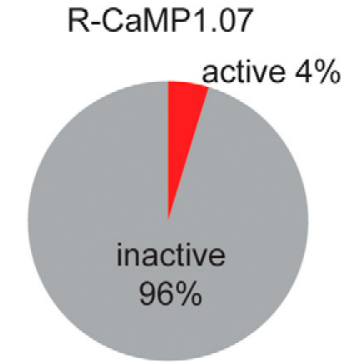

Isoflurane

$\mathbf{F}$

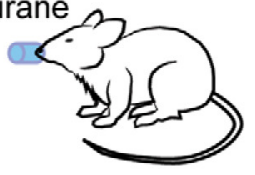

GCaMP6s

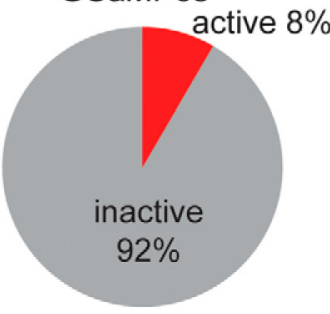

Figure 2. In vivo calcium imaging of DG granule cell activity in anesthetized mice. $\boldsymbol{A}$, In vivo two-photon images of R-CaMP1.07-expressing DG granule cells in an anesthetized, head-fixed mouse. The right panel shows the imaging field. $\boldsymbol{B}, \Delta F / F$ calcium traces for 12 example neurons from the neuronal population shown in $\boldsymbol{A}$. Example traces are shown for granule cells displaying no activity (gray) or for cells exhibiting large $\Delta F / F$ transients (red). Red arrows in $\boldsymbol{A}$ correspond to the two neurons active in this session. $\boldsymbol{C}$, Percentage of R-CaMP1.07-expressing cells showing activity during isoflurane anesthesia. $\boldsymbol{D}$, In vivo two-photon images of GCaMP6s-expressing DG granule cells in an anesthetized, head-fixed mouse. The right panel shows the imaging field. $\boldsymbol{E}, \Delta F / F$ calcium traces for 13 example neurons from the neuronal population shown in $\boldsymbol{D}$. Example traces for inactive (gray) and active (red) granule cells. Red arrows in $\boldsymbol{D}$ correspond to the three neurons showing large calcium transients in this session. $\boldsymbol{F}$, Percentage of GCaMP6s-expressing granule cells showing activity during isoflurane anesthesia. Scale bars: $\boldsymbol{A}, \mathbf{D}$, left, $50 \mu \mathrm{m}$; right, $20 \mu \mathrm{m}$. dpi, Days postinjection.

R-CaMP1.07 and GCaMP6s, respectively. Image analysis was performed using Fiji software (Schindelin et al., 2012).

Behavioral testing. For open-field behavioral testing, unoperated animals were placed in the center of a squared arena $(45 \times 45 \times 40$ $\mathrm{cm})$ made from gray Plexiglas that was illuminated from a centered diffuse light source. Single animals were allowed to explore the open field for 10 min while being recorded by a video camera placed above the open field and operated by LabView (National Instruments). Movies were analyzed with MATLAB, extracting the distance traveled by the animals and the frequency of rearing events as assessed by manual scoring. After the first behavioral testing, six animals received viral injections (R-CaMP1.07 or GCaMP6s) into the DG and hippocampal window implantation, whereas four control animals received viral injections but no window implant. Two weeks after implantation of the hippocampal window, open-field testing was repeated for both the operated and the sham-operated group. Analysis was performed using paired or unpaired $t$ test (Excel) for intraindividual and group comparisons, respectively.

Two-photon calcium imaging. We used a custom-built, two-photon microscope of the Sutter Instrument Movable Objective Microscope type, equipped with a $16 \times$ long-working-distance, water-immersion objective (0.8 numerical aperture, model CFI75 LWD $16 \times$ W, Nikon), a Pockels cell (model 350/80 with controller model 302RM, Conoptics), and galvanometric scan mirrors (model 6210, Cambridge Technology), controlled by HelioScan software (Langer et al., 2013). For excitation of R-CaMP1.07, we used a ytterbium-doped potassium gadolinium tungstate (Yb:KGW) laser $(1040 \mathrm{~nm},>2 \mathrm{~W}$ average power, $\sim 230 \mathrm{fs}$ pulses at $80 \mathrm{MHz}$; model Ybix, Time Bandwidth Products). GCaMP6s was excited at $920 \mathrm{~nm}$ with a standard Ti:sapphire laser system $(\sim 100 \mathrm{fs}$ laser pulse width; Mai Tai HP, Newport). Fluorescence was collected with a red emission filter (610/75 nm; AHF Analysetechnik). In experiments under anesthesia, the average laser power beneath the objective for exciting R-CaMP1.07 and GCaMP6s in the granule cell layer was $239 \pm 104 \mathrm{~mW}$ and $141 \pm 44 \mathrm{~mW}$, respectively (mean $\pm \mathrm{SD}$ ). In awake experiments, the average laser power was $234 \pm 75 \mathrm{~mW}$ and $133 \pm 50 \mathrm{~mW}$, respectively. We estimate that the laser power in the focal volume $(600-800 \mu \mathrm{m}$ deep in the tissue) was $>10-40$ times lower, assuming a scattering length of $200-250 \mu \mathrm{m}$ at $920-1040 \mathrm{~nm}$ (Kobat et al., 2009). Laser intensity presumably was also attenuated by scattering in the white matter tract of the corpus callosum and potentially by clipping of the beam at the window implant edges.

For imaging experiments under anesthesia, each mouse was anesthetized with isoflurane ( $2 \%$ in oxygen) and fixed with their aluminum head post to a holder to keep the animal stable during imaging. Body temperature was constantly monitored and kept at $37^{\circ} \mathrm{C}$ with a heating pad. Normal Ringer's solution [containing (in $\mathrm{mm}$ ) $135 \mathrm{NaCl}$, $5.4 \mathrm{KCl}, 5 \mathrm{HEPES}, 1.8 \mathrm{CaCl}_{2}$, pH 7.2] was used as immersion medium for the $16 \times$ water-immersion objective. For awake experiments, the mouse was head fixed under the microscope objective and placed on top of a running ladder wheel $(\varnothing 20 \mathrm{~cm})$ with regularly spaced rungs (1 cm spacing). Running speed and running distance were recorded at $40 \mathrm{~Hz}$ with a rotary encoder and synchronized to calcium imaging of granule cell populations. In imaging sessions, the activity of calcium indicator-expressing granule cells was recorded in trials of $20 \mathrm{~s}$ duration, interleaved with 10-s-long breaks without laser illumination and recording (maximum number of trials, $n=30$ ). Animals were kept under these running and recording conditions maximally for $45 \mathrm{~min}$ per session.

Data analysis and statistics. Calcium indicator fluorescence signals, $F$, were analyzed using custom software routines in Fiji, MATLAB (MathWorks), and IGOR (Wavemetrics). We subtracted background fluorescence (estimated as the bottom first percentile fluorescence signal across the entire movie) and applied a hidden Markov model line-by-line motion correction algorithm (Dombeck et al., 2007). Trials obviously insufficiently motion corrected were excluded from the analysis. In some case, images were spatially smoothed with a 
Gaussian filter (1 pixel width). Regions of interests corresponding to individual neurons were manually selected from the mean image of a single-trial time series. Background- and motion-corrected calcium signals were expressed as the relative percentage change, $\Delta F / F=\left(F-F_{0}\right) / F_{0}$, where $F_{0}$ was calculated as the eighth percentile of the distribution of fluorescence values. $\Delta F / F$ traces were smoothed with a five-point, firstorder Savitsky-Golay filter. "Large" calcium transients were detected based on the following criteria: First, a $\Delta F / F$ baseline was calculated as the fifth percentile of the mean fluorescence in an $8 \mathrm{~s}$ sliding window, and baseline noise was taken as the first percentile of the SD values obtained in an $8 \mathrm{~s}$ sliding window. Fluorescence transients were considered large when their peak amplitude deviated from baseline more than three times the baseline noise for R-CaMP1.07 (four times for GCaMP6s). Second, the peak $\Delta F / F$ amplitude had to be at least $25 \%$. Third, two consecutive peaks had to be separated by at least $800 \mathrm{~ms}$ to avoid detection of calcium transient shoulders.

To quantify the decay kinetics of calcium transients, we selected isolated salient calcium transients $(>50 \% \Delta F / F)$ and fitted an exponential curve to the decay phase, revealing a significantly faster time constant for granule cells expressing R-CaMP1.07 compared to those expressing GCaMP6s $(1.47 \pm 0.71 \mathrm{~s}$ vs $2.12 \pm 1.26 \mathrm{~s} ; n=38$ and 47 events, respectively; mean $\pm \mathrm{SD} ; p<0.01$, unpaired $t$ test). As our analysis was focused on detection of calcium transients rather than their time course, the results are nonetheless consistent for the two indicators.

We counted the frequency of large calcium transients across different behavioral conditions. Running speed was downsampled to the imaging frame rate $(10 \mathrm{~Hz})$; periods with speeds larger than $0.5 \mathrm{~cm} / \mathrm{s}$ were considered "running" periods, and periods with speeds between -0.5 and $0.5 \mathrm{~cm} / \mathrm{s}$ were considered "rest" periods. Values below $-0.5 \mathrm{~cm} / \mathrm{s}$ were ignored and not included in either running or resting periods. Cells with a calcium transient frequency larger than $0.01 \mathrm{~min}^{-1}$ were considered active and otherwise were considered inactive. Active cells were further classified as being preferentially active in running or resting periods, or in both, as follows: We resampled our fluorescence data using a modified bootstrapping method. Randomly sampled 1-s-long traces were concatenated to create fluorescence traces of the same length of the original data. We repeated this 100 times and computed the mean frequency of events during running and resting periods $\left(f_{\text {run }}, f_{\text {rest }}\right)$ as well as their SD values $\left(\sigma_{\text {run }}, \sigma_{\text {rest }}\right)$. As a sensitivity index, we calculated the $d^{\prime}$ value:

$$
d^{\prime}=\frac{f_{r u n}+f_{\text {rest }}}{\sqrt{\frac{1}{2}\left(\sigma_{r u n}^{2}+\sigma_{r e s t}^{2}\right)}} .
$$

Cells with $d^{\prime}>1.8$ were considered run cells, cells with $d^{\prime}<-1.8$ were considered rest cells, and cells with $d^{\prime}$ between -1.8 and 1.8 were labeled as being active during both conditions. Any active cell for which the total duration of either run or resting periods was $<5 \%$ of the recording time was labeled as "uncharacterized" because no reliable statement was possible about preference in this case. Characterization was based on the activity on individual imaging days. Pie charts of neuronal preference (see Fig. 4A) were computed using data from only the first day of recording of each neuron. Repeated measurements from the same neurons were not pooled. Statistical analysis was performed using an unpaired $t$ test (Excel).
B

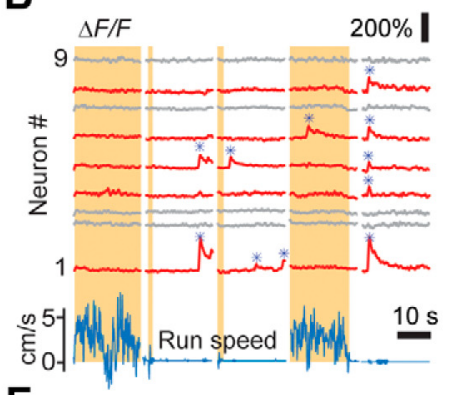

E

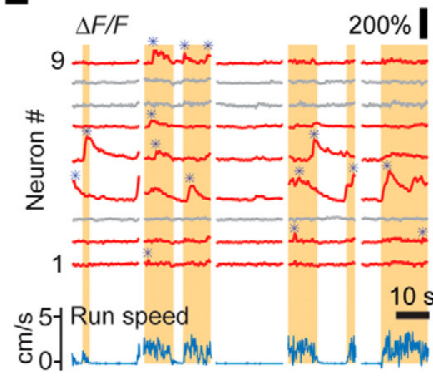

C

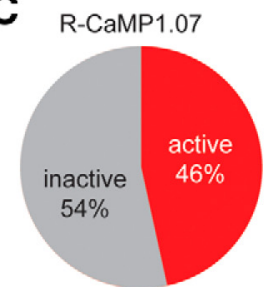

$\mathbf{F}$
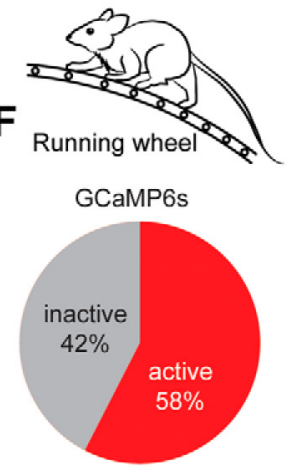

Figure 3. In vivo calcium imaging of $D G$ granule cell activity in awake mice. $A$, In vivo two-photon images of R-CaMP1.07shown as subscripts in $A$ ). Neuronal traces displaying large $\Delta F / F$ transients are marked in red and the run speed is denoted in blue. Note the enhanced activity in the awake state and the similar activity of individual neurons during the resting

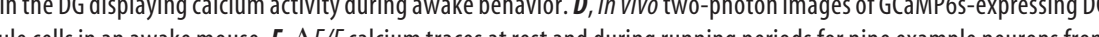
the neuronal population shown in $\boldsymbol{D}$ (cell numbers are indicated in $\boldsymbol{D}$ ). Note the number of cells being active during running periods. Detected large calcium transients are depicted with blue asterisks. $\boldsymbol{F}$, Percentage of GCaMP6s-labeled granule cells displaying calcium activity during the awake state. Scale bars: $20 \mu \mathrm{m}$.

Responses to either locomotion start or end were evaluated by first aligning neuronal calcium traces to the onset and offset of running periods, respectively, and averaging across all instances for both conditions. If the peak amplitude (after smoothing with a nine-point Savitzky-Golay filter) in a $3 \mathrm{~s}$ time window following the transition exceeded five times the $\mathrm{SD}$ in a $0.9 \mathrm{~s}$ pretransition window, the response was considered significant.

\section{Results}

Cell type-specific expression of genetically encoded calcium indicators in dentate granule cells

To allow for functional imaging of DG granule cells, we expressed either the red fluorescent calcium indicator R-CaMP1.07 (Ohkura et al., 2012) or the green fluorescent calcium indicator GCaMP6s (Chen et al., 2013) in granule cells by injecting a Credependent AAV into the DGs of transgenic mice expressing Cre recombinase under the control of the regulatory elements of the retinol binding protein $4(R b p 4)$ gene that is highly expressed in distinct DG granule cells (and other neuronal cells outside the DG such as layer 5 cortical neurons; Gerfen et al., 2013). This approach resulted in specific labeling of DG granule cells within the adult hippocampus as verified by post hoc histological staining using Prox1, a homeobox-domain transcription factor that is selectively expressed in granule cells in the adult mouse forebrain (Karalay et al., 2011; Fig. 1A-C; see Materials and Methods). To provide optical access to the hippocampus for in vivo imaging, we locally removed overlying cortical tissue by aspiration and subsequently implanted a chronic window (Mizrahi et al., 2004; Dombeck et al., 2010; Gu et al., 2014). The hippocampus itself and the overlying corpus callosum remained unharmed to avoid 
A

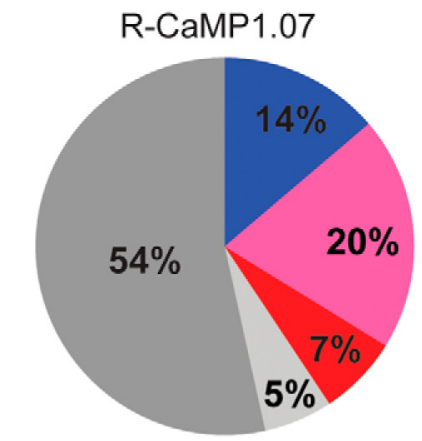

Running

Both

Resting

Uncharacterized

Inactive

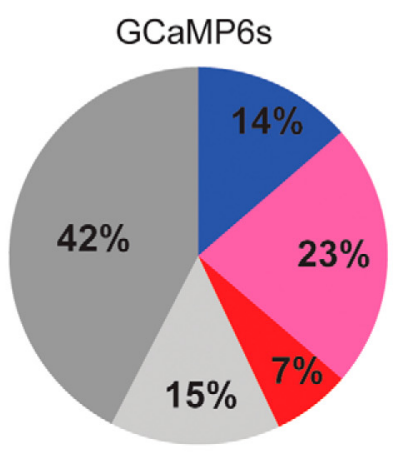

B

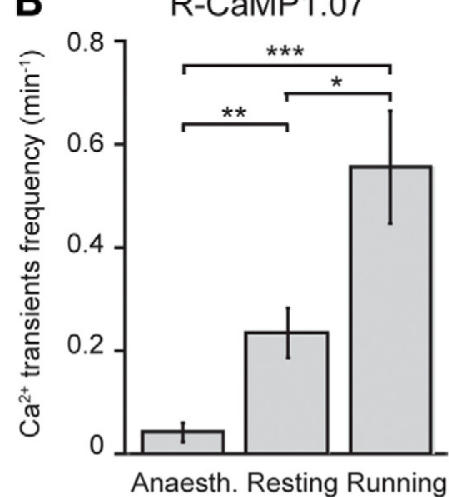

C

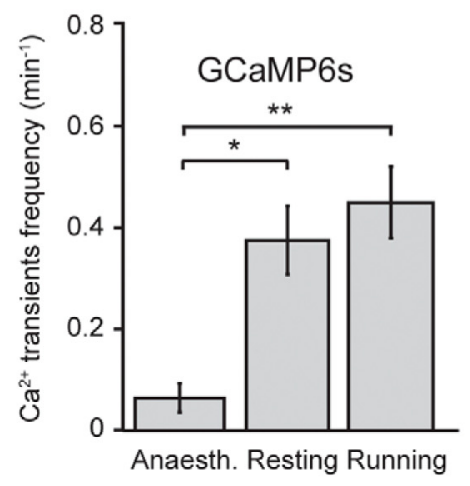

D

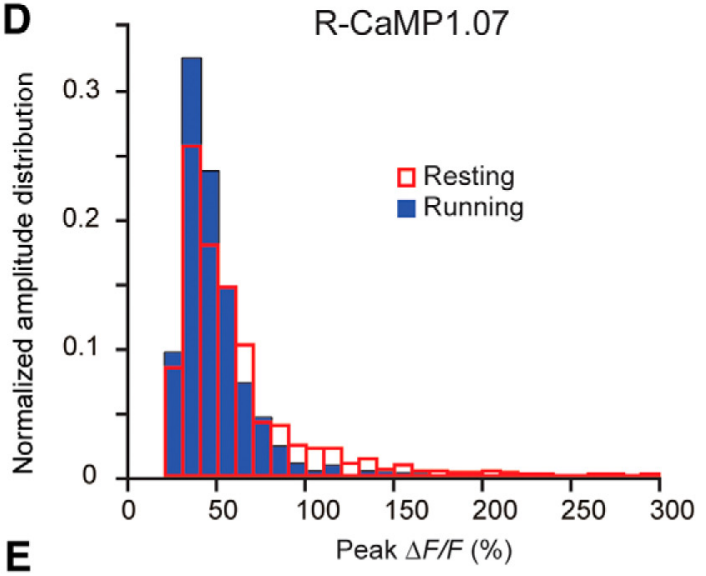

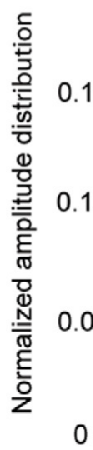

GCaMP6s

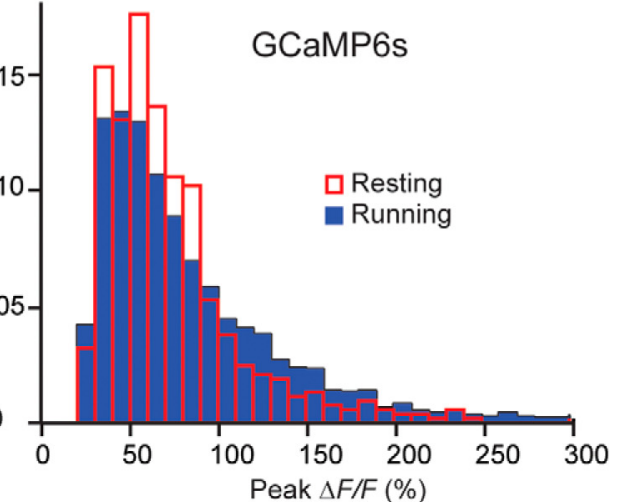

Figure 4. Heterogeneous association of dentate granule cell activity in awake mice with locomotion. $\boldsymbol{A}$, Preferential activity during running and resting periods of R-CaMP1.07-expressing (top pie chart, $n=$ 479 cells from 9 animals) and GCaMP6s-expressing DG granule cells (bottom pie chart, $n=363$ cells from 4 animals). Activity preference of cells was classified based on a $d$ ' selectivity index (see Materials and Methods). Running (blue) and resting (red) cells showed clear preference for one state (absolute $d^{\prime}>1.8$ ). A fraction of granule cells exhibited similar rates of activity during both running and resting periods (pink). Granule cells labeled "uncharacterized" showed periods of either resting or running that were too short for a preference analysis. $B, C$, Mean frequency of large $\Delta F / F$ transients in DG granule cells during anesthesia and during resting or running in awake mice across the entire data sets for R-CaMP1.07 (B) and GCaMP6s (C). D, E, Distribution of peak amplitudes of large $\Delta F / F$ calcium transients in DG granule cells during resting and running periods for R-CaMP1.07 (D) and GCaMP6s $(\boldsymbol{E}) .{ }^{*} p<0.05 ;{ }^{* *} p<0.01 ;{ }^{* * *} p<0.001$. Error bars indicate SE.

interference with hippocampal/entorhinal cortex (EC) circuit integrity (Bonnevie et al., 2013). We assessed potential behavioral effects in an open-field test. Window implantation affected neither the distance traveled in $10 \mathrm{~min}(3.55 \pm 0.76 \mathrm{~m}$ before, $3.57 \pm 1.39 \mathrm{~m}$ after, mean $\pm \mathrm{SD} ; n=6$; $p>0.9$, paired $t$ test) nor the frequency of rearing events $\left(4.45 \pm 1.27 \mathrm{~min}^{-1}\right.$ before, $4.28 \pm 2.27 \mathrm{~min}^{-1}$ after; $\left.p>0.8\right)$. These values were also not significantly different from sham-operated mice $(n=$ $4 ; p>0.1$, unpaired $t$ test).

\section{R-CaMP1.07 and GCaMP6s allow for in vivo granule cell imaging}

Two-photon excitation at $1040 \mathrm{~nm}$ with a fixed-wavelength femtosecond laser allowed for imaging of R-CaMP1.07expressing granule cells at $600-800 \mu \mathrm{m}$ below the corpus callosum (Fig. 2A-C). GCaMP6s excited with a tunable Ti: sapphire laser at $920 \mathrm{~nm}$ could also be robustly detected in the granule cell layer of the DG (Fig. $2 D-F$ ). We first measured calcium transients in granule cell populations in anesthetized mice $(n=7)$. Consistent across mice, only a small fraction of granule cells displayed occasional large $\Delta F / F$ transients ( $>25 \%$; see Material and Methods) over $1-3$ min recording periods ( $4 \%$ of R-CaMP1.07-positive cells, $n=695$ cells from 16 imaging areas of 5 mice; $8 \%$ of GCaMP6s-positive cells, $n=$ 238 cells from 4 imaging areas from 2 mice; Fig. $2 B, E$ ). These large calcium signals presumably reflect bursts of action po-

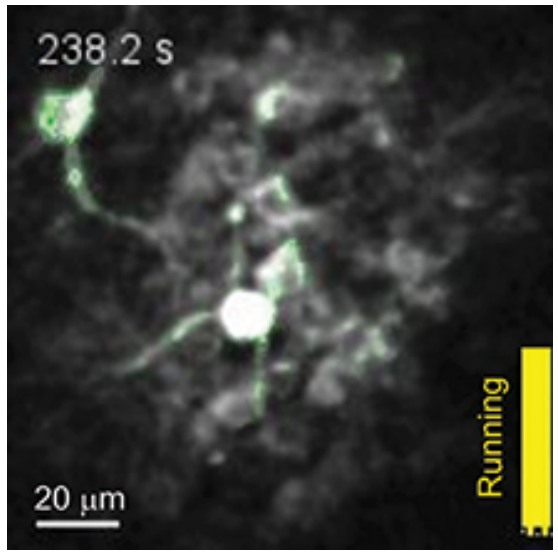

Movie 1. Example movie of in vivo DG granule cell activity, corresponding to the recording shown in Figure $3 A$ ( 28 d postinjection). $\Delta F / F$ changes are overlaid in green. The right yellow bar indicates the momentary running speed. Movie speed, $20 \times$ accelerated. Scale bar, 20 $\mu \mathrm{m}$.

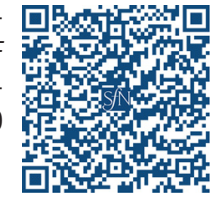

tentials, given estimates of $5-15 \% \Delta F / F$ changes for single action potential-evoked R-CaMP1.07 transients in neocortical pyramidal neurons (Ohkura et al., 2012; Inoue et al., 2015; our unpublished data). Because the sensitivity of R-CaMP1.07 and 

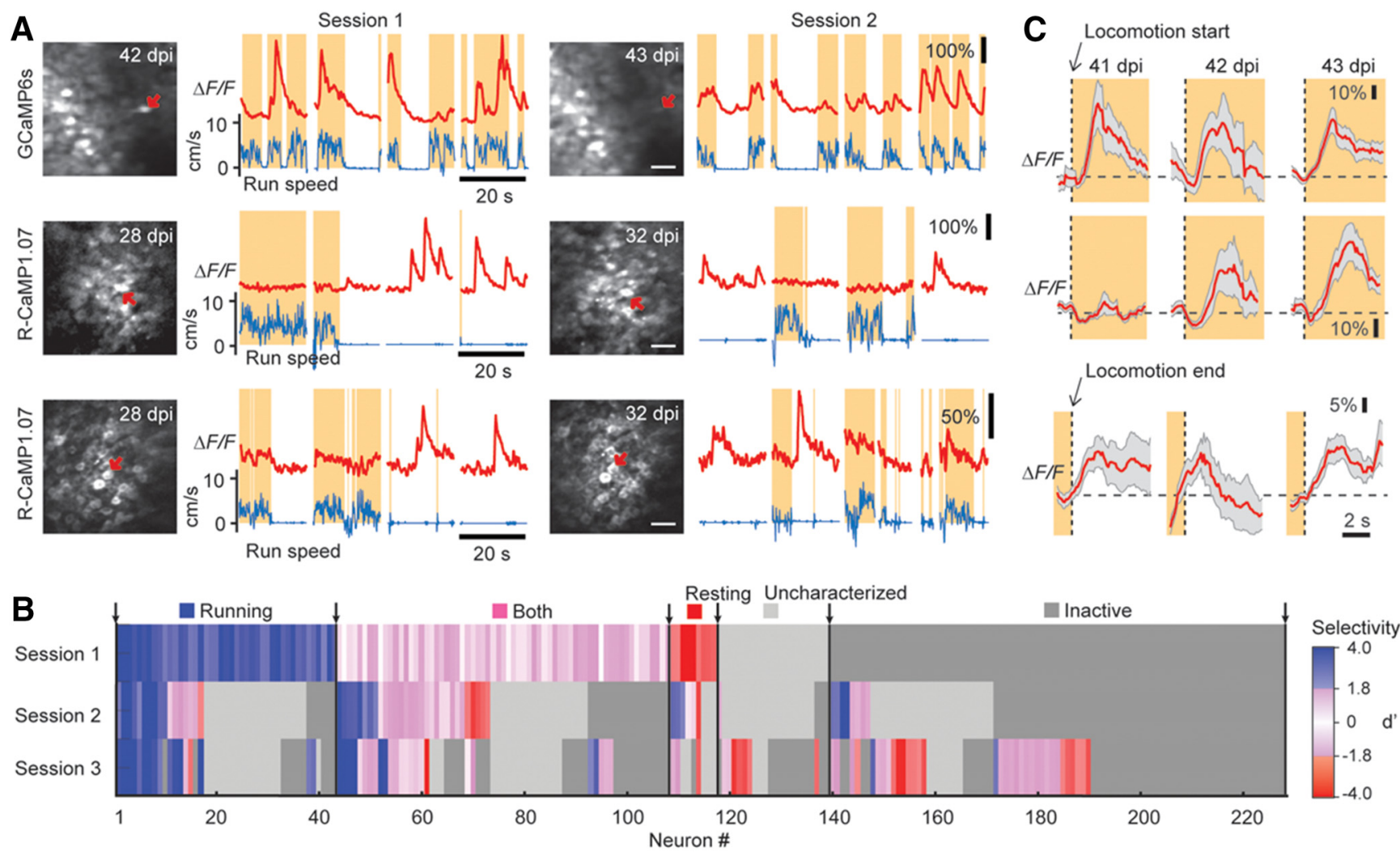

Figure 5. Repeated imaging of granule cell activity across several days. $A$, Example calcium traces for three granule cells measured in two separate imaging sessions 1 to several days apart. Two cells were consistently active specifically in either the running state (top row) or during resting (middle row); the cell in the bottom row changed its activity pattern from being active in resting states to being active during both states. $\boldsymbol{B}$, Summary plot depicting the specificity of activation pattern for all granule cells repeatedly imaged in three consecutive sessions across several days pooled from R-CaMP1.07 and GCaMP6s experiments ( $n=228$ cells). Activity preference of cells was classified based on a $d^{\prime}$ selectivity index as running (blue), resting (red), or both (pink), or remained uncharacterized (light gray). Inactive cells are depicted in dark gray (see Materials and Methods). Shading was applied according to the absolute $d^{\prime}$ value to indicate strength of selectivity. C, Example traces for three individual, chronically imaged GCaMP6s-expressing cells from one imaging area exhibiting significant calcium responses aligned to the start (Cells 1 and 2, top and middle rows, respectively) or end (Cell 3, bottom row) of running activity. Note that cells either showed a consistent activation at the start (top) or end (bottom) of running periods in multiple sessions across days or displayed changes in their activation pattern like the example neuron in the middle row. Scale bars, $30 \mu \mathrm{m}$.

GCaMP6s for reporting action potential-evoked calcium transients has not been calibrated in DG granule cells so far, we cannot exclude that low-frequency baseline spiking remained undetected. Nonetheless, results obtained with both R-CaMP1.07 and GCaMP6s in anesthetized mice indicate very low spiking activity of adult granule cells, in agreement with previous reports that showed relative sparseness of DG activity using in vivo electrophysiological recordings and during in vivo imaging (Jung and McNaughton, 1993; Leutgeb et al., 2007; Alme et al., 2010; Danielson et al., 2016).

\section{R-CaMP1.07 and GCaMP6s allow granule cell imaging in awake mice}

After showing that imaging of dentate circuits is feasible in anesthetized mice, we next aimed to assess DG granule cell activity in awake mice during various behavioral states. Mice were adapted to head fixation and to running on top of a ladder wheel (see Materials and Methods). We acquired two-photon image series of R-CaMP1.07 fluorescence and GCaMP6s fluorescence in DG granule cell populations (Fig. $3 A-F$ ). Compared to the anesthetized condition, a higher fraction of neurons displayed large $\Delta F / F$ transients for both calcium indicators (Fig. 3C,F; 46\% of R-CaMP1.07-expressing cells; $n=479$ cells from 10 imaging areas of 7 mice; $58 \%$ of GCaMP6s-expressing cells; $n=363$ cells from 5 imaging areas of 4 mice; Fig. $3 B, E)$.
Interestingly, we identified subpopulations of DG granule cells that showed robust activity preferentially during either resting or running (Fig. $3 B, E$, respectively), suggesting locomotionassociated activity patterns of DG granule cells similar to what has been described previously for CA1 pyramidal cells (McNaughton et al., 1983; Fuhrmann et al., 2015). Of all cells displaying large calcium transients, slightly more cells were preferentially active during running periods compared to resting conditions (Fig. 4A). Approximately $20 \%$ of cells displayed activity in both states, running and resting, in experiments with both R-CaMP1.07 and GCaMP6s (Fig. 4A). Although the frequency of occurrence of large calcium transients was significantly higher in awake mice than during anesthesia (Fig. $4 B, C$ ), the overall rates across the entire population of about one event per cell every $2-5$ min still indicates sparse DG activity. The amplitude distributions of the calcium transients revealed a trend of large calcium transients occurring more frequently during the resting state for labeling with R-CaMP1.07. This finding may indicate enhanced burstiness of DG granule cells during nonrunning periods (Fig. $4 D$, Movie 1). However, GCaMP6s-labeled dentate granule cells, in contrast, displayed larger amplitudes during running periods (Fig. 4E). We conclude that granule cells show a spectrum of behavior-dependent activity patterns, with distinct preferences of individual cells. 


\section{Chronic imaging of R-CaMP1.07- and GCaMP6s-expressing granule cells reveals functional flexibility of dentate granule cells}

Strikingly, the activity of granule cells could be monitored repeatedly across several days (Fig. $5 A$ ), indicating the required stability of in vivo optical imaging that will allow for analyzing the functional activation of individual granule cells during distinct experiences in awake mice. Using such a chronic imaging approach, we found examples of both consistency in activity in three consecutive imaging sessions across several days (i.e., neurons specifically active only during resting or running periods) and more flexible behavior-dependent activity (e.g., neurons changing from preferred activity during resting to being active in both states; Fig. $5 A, B$ ). From Session 1 to Session 2, a fraction of $45 \%$ (103 of 228 cells) retained their preference for a behavioral state, whereas from Session 1 to Session 3, this was the case for only $25 \%$ of cells ( 58 of 228 cells; Fig. $5 B$ ). This finding indicates a pronounced flexibility and relatively low stability of behavioralstate-related granule cell activity over prolonged time periods. Interestingly, we also observed neurons that exhibited large calcium transients specifically at either the start or end of running periods (Fig. 5C; $\sim 36 \%$ and 10\% for locomotion onset and offset, respectively; $n=209$ cells in 3 mice). In several cases, the temporal locking of their activation to run start or run end was stable across consecutive imaging sessions, but we also observed cells that changed their activation pattern (Fig. 5C), indicating functional flexibility of dentate granule cells.

\section{Discussion}

Our study provides the first proof of principle that the hippocampal DG granule cell population is amenable to functional imaging studies in vivo with an approach that leaves the hippocampal formation intact. This was achieved by using both a red-shifted calcium indicator that can be efficiently two-photon excited above $1000 \mathrm{~nm}$ (Ohkura et al., 2012; Inoue et al., 2015) and also a more conventional green calcium indicator (Chen et al., 2013). Red fluorescent indicators, of which new variants have been introduced recently (Dana et al., 2016), are particularly suitable for facilitating deep tissue imaging. Notably, our chronic window implantation allows for repeated imaging in DG in fully awake mice. This will make it possible to study the activity patterns of granule cells as well as other targeted neuronal populations in the DG for more complex behaviors, e.g., locomotion or navigation in a virtual space (Dombeck et al., 2010; Harvey et al., 2012). In addition, optical imaging of granule cell activity will allow for characterization of activation patterns during distinct phases (i.e., encoding vs retrieval) of dentate-dependent learning and memory tasks adapted to head-fixed experimental settings (Clelland et al., 2009; Deng et al., 2013). Excitingly, the approach described here suggests that simultaneous imaging in two distinct color channels (e.g., combining red and green calcium indicators) to test the functional behavior of two select neuronal populations appears feasible.

Most recently, chronic imaging experiments of newborn and mature granule cells were described that found relatively high rates of remapping both in old and newborn granule cells when animals were exposed to different contextual experiences (Danielson et al., 2016). These are exciting data that support the feasibility of chronic DG in vivo imaging. However, and in contrast to our approach that leaves the hippocampus intact, Danielson et al. (2016) used a preparation that at least partially lesions hippocampal area CA1, which may substantially affect the functionality of hippocampal/EC circuitries (Bonnevie et al., 2013; Danielson et al., 2016). Be that as it may, the substantial rate of remapping of spatial representations (Bonnevie et al., 2013; Danielson et al., 2016) and the flexibility of granule cell activity in relation to behavioral-state preference (i.e., running vs resting) shown here both suggest that granule cell activation patterns in the adult DG change across days, presumably undergoing context- and experience-dependent plasticity. Together with previously described approaches allowing for structural imaging of the DG (Gu et al., 2014; Kawakami et al., 2015), the method described here will substantially expand the available toolbox to analyze granule cell activity in an intact hippocampal circuitry to study the mechanisms underlying functional (e.g., experienceinduced) and structural (e.g., neurogenesis-associated) plasticity of the adult DG.

\section{References}

Alme CB, Buzzetti RA, Marrone DF, Leutgeb JK, Chawla MK, Schaner MJ, Bohanick JD, Khoboko T, Leutgeb S, Moser EI, Moser MB, McNaughton BL, Barnes CA (2010) Hippocampal granule cells opt for early retirement. Hippocampus 20:1109-1123. CrossRef Medline

Amaral DG, Scharfman HE, Lavenex P (2007) The dentate gyrus: fundamental neuroanatomical organization (dentate gyrus for dummies). Prog Brain Res 163:3-22. CrossRef Medline

Bonnevie T, Dunn B, Fyhn M, Hafting T, Derdikman D, Kubie JL, Roudi Y, Moser EI, Moser MB (2013) Grid cells require excitatory drive from the hippocampus. Nat Neurosci 16:309-317. CrossRef Medline

Chen TW, Wardill TJ, Sun Y, Pulver SR, Renninger SL, Baohan A, Schreiter ER, Kerr RA, Orger MB, Jayaraman V, Looger LL, Svoboda K, Kim DS (2013) Ultrasensitive fluorescent proteins for imaging neuronal activity. Nature 499:295-300. CrossRef Medline

Clelland CD, Choi M, Romberg C, Clemenson GD Jr, Fragniere A, Tyers P, Jessberger S, Saksida LM, Barker RA, Gage FH, Bussey TJ (2009) A functional role for adult hippocampal neurogenesis in spatial pattern separation. Science 325:210-213. CrossRef Medline

Dana H, Mohar B, Sun Y, Narayan S, Gordus A, Hasseman JP, Tsegaye G, Holt GT, Hu A, Walpita D, Patel R, Macklin JJ, Bargmann CI, Ahrens MB, Schreiter ER, Jayaraman V, Looger LL, Svoboda K, Kim DS (2016) Sensitive red protein calcium indicators for imaging neural activity. Elife 5:e12727. Medline

Danielson NB, Kaifosh P, Zaremba JD, Lovett-Barron M, Tsai J, Denny CA, Balough EM, Goldberg AR, Drew LJ, Hen R, Losonczy A, Kheirbek MA (2016) Distinct contribution of adult-born hippocampal granule cells to context encoding. Neuron 90:101-112 CrossRef Medline

Deng W, Mayford M, Gage FH (2013) Selection of distinct populations of dentate granule cells in response to inputs as a mechanism for pattern separation in mice. Elife 2:e00312. Medline

Dombeck DA, Khabbaz AN, Collman F, Adelman TL, Tank DW (2007) Imaging large-scale neural activity with cellular resolution in awake, mobile mice. Neuron 56:43-57. CrossRef Medline

Dombeck DA, Harvey CD, Tian L, Looger LL, Tank DW (2010) Functional imaging of hippocampal place cells at cellular resolution during virtual navigation. Nat Neurosci 13:1433-1440. CrossRef Medline

Fuhrmann F, Justus D, Sosulina L, Kaneko H, Beutel T, Friedrichs D, Schoch S, Schwarz MK, Fuhrmann M, Remy S (2015) Locomotion, theta oscillations, and the speed-correlated firing of hippocampal neurons are controlled by a medial septal glutamatergic circuit. Neuron 86:1253-1264. CrossRef Medline

Gerfen CR, Paletzki R, Heintz N (2013) GENSAT BAC cre-recombinase driver lines to study the functional organization of cerebral cortical and basal ganglia circuits. Neuron 80:1368-1383. CrossRef Medline

Gu L, Kleiber S, Schmid L, Nebeling F, Chamoun M, Steffen J, Wagner J, Fuhrmann M (2014) Long-term in vivo imaging of dendritic spines in the hippocampus reveals structural plasticity. J Neurosci 34:1394813953. CrossRef Medline

Harvey CD, Coen P, Tank DW (2012) Choice-specific sequences in parietal cortex during a virtual-navigation decision task. Nature 484:62-68. CrossRef Medline

Inoue $\mathrm{M}$, Takeuchi A, Horigane S, Ohkura M, Gengyo-Ando K, Fujii H, Kamijo S, Takemoto-Kimura S, Kano M, Nakai J, Kitamura K, Bito H 
(2015) Rational design of a high-affinity, fast, red calcium indicator R-CaMP2. Nat Methods 12:64-70. Medline

Jonas P, Lisman J (2014) Structure, function, and plasticity of hippocampal dentate gyrus microcircuits. Front Neural Circuits 8:107. Medline

Jung MW, McNaughton BL (1993) Spatial selectivity of unit activity in the hippocampal granular layer. Hippocampus 3:165-182. CrossRef Medline

Karalay O, Doberauer K, Vadodaria KC, Knobloch M, Berti L, Miquelajauregui A, Schwark M, Jagasia R, Taketo MM, Tarabykin V, Lie DC, Jessberger S (2011) Prospero-related homeobox 1 gene (Prox1) is regulated by canonical Wnt signaling and has a stage-specific role in adult hippocampal neurogenesis. Proc Natl Acad Sci U S A 108:5807-5812. CrossRef Medline

Kawakami R, Sawada K, Kusama Y, Fang YC, Kanazawa S, Kozawa Y, Sato S, Yokoyama H, Nemoto T (2015) In vivo two-photon imaging of mouse hippocampal neurons in dentate gyrus using a light source based on a high-peak power gain-switched laser diode. Biomed Opt Express 6:891901. CrossRef Medline

Kobat D, Durst ME, Nishimura N, Wong AW, Schaffer CB, Xu C (2009) Deep tissue multiphoton microscopy using longer wavelength excitation. Opt Express 17:13354-13364. CrossRef Medline

Langer D, van 't Hoff M, Keller AJ, Nagaraja C, Pfäffli OA, Göldi M, Kasper H, Helmchen F (2013) HelioScan: a software framework for controlling in vivo microscopy setups with high hardware flexibility, functional diversity and extendibility. J Neurosci Methods 215:38-52. CrossRef Medline

Lee SH, Marchionni I, Bezaire M, Varga C, Danielson N, Lovett-Barron M, Losonczy A, Soltesz I (2014) Parvalbumin-positive basket cells differentiate among hippocampal pyramidal cells. Neuron 82:11291144. CrossRef Medline

Leutgeb JK, Leutgeb S, Moser MB, Moser EI (2007) Pattern separation in the dentate gyrus and CA3 of the hippocampus. Science 315:961-966. CrossRef Medline

Levene MJ, Dombeck DA, Kasischke KA, Molloy RP, Webb WW (2004) In vivo multiphoton microscopy of deep brain tissue. J Neurophysiol 91: 1908-1912. CrossRef Medline

McNaughton BL, Barnes CA, O'Keefe J (1983) The contributions of position, direction, and velocity to single unit activity in the hippocampus of freely-moving rats. Exp Brain Res 52:41-49. Medline
Mizrahi A, Crowley JC, Shtoyerman E, Katz LC (2004) High-resolution in vivo imaging of hippocampal dendrites and spines. J Neurosci 24: 3147-3151. CrossRef Medline

Nakashiba T, Cushman JD, Pelkey KA, Renaudineau S, Buhl DL, McHugh TJ, Rodriguez Barrera V, Chittajallu R, Iwamoto KS, McBain CJ, Fanselow MS, Tonegawa S (2012) Young dentate granule cells mediate pattern separation, whereas old granule cells facilitate pattern completion. Cell 149:188-201. CrossRef Medline

Neunuebel JP, Knierim JJ (2014) CA3 retrieves coherent representations from degraded input: direct evidence for CA3 pattern completion and dentate gyrus pattern separation. Neuron 81:416-427. CrossRef Medline

Ohkura M, Sasaki T, Kobayashi C, Ikegaya Y, Nakai J (2012) An improved genetically encoded red fluorescent $\mathrm{Ca} 2+$ indicator for detecting optically evoked action potentials. PLoS One 7:e39933. CrossRef Medline

Rickgauer JP, Deisseroth K, Tank DW (2014) Simultaneous cellularresolution optical perturbation and imaging of place cell firing fields. Nat Neurosci 17:1816-1824. CrossRef Medline

Sahay A, Scobie KN, Hill AS, O'Carroll CM, Kheirbek MA, Burghardt NS, Fenton AA, Dranovsky A, Hen R (2011) Increasing adult hippocampal neurogenesis is sufficient to improve pattern separation. Nature 472 : 466-470. CrossRef Medline

Schindelin J, Arganda-Carreras I, Frise E, Kaynig V, Longair M, Pietzsch T, Preibisch S, Rueden C, Saalfeld S, Schmid B, Tinevez JY, White DJ, Hartenstein V, Eliceiri K, Tomancak P, Cardona A (2012) Fiji: an opensource platform for biological-image analysis. Nat Methods 9:676-682. CrossRef Medline

Sheffield ME, Dombeck DA (2015) Calcium transient prevalence across the dendritic arbour predicts place field properties. Nature 517:200-204. Medline

Spalding KL, Bergmann O, Alkass K, Bernard S, Salehpour M, Huttner HB, Boström E, Westerlund I, Vial C, Buchholz BA, Possnert G, Mash DC, Druid H, Frisén J (2013) Dynamics of hippocampal neurogenesis in adult humans. Cell 153:1219-1227. CrossRef Medline

Ziv Y, Burns LD, Cocker ED, Hamel EO, Ghosh KK, Kitch LJ, El Gamal A, Schnitzer MJ (2013) Long-term dynamics of CA1 hippocampal place codes. Nat Neurosci 16:264-266. CrossRef Medline 